\title{
JUVENILE HORMONE AND VITELLOGENIN SYNTHESIS IN THE CECROPIA SILKWORM
}

\author{
M. L. PAN ${ }^{1}$
}

\section{Department of Zoology, The University of Tennessee, Knoxville, Tennessee 37916}

In many insect representatives from a broad spectrum of orders, vitellogenesis is controlled by juvenile hormone secreted by the corpora allata (see reviews by Telfer, 1965 ; Engelmann, 1970). Notable exceptions to this finding have been the saturniid moths (Lepidoptera: Saturniidae), in which the removal of the corpora allata from the pupa has no detectable effect on the production of eggs several weeks later ( see Williams, 1952).

As first demonstrated by Telfer (1965), yolk formation in insects entails the sequestering of one or more sex-limited hemolymph proteins, the vitellogenins (Pan, Bell and Telfer, 1969). The synthesis of vitellogenins in the fat body in many nonsaturniid insects requires juvenile hormone (see reviews by Wyatt, 1972; Doane, 1973). This observation raises the possibility that the failure of allatectomy to affect egg formation in saturniids may be related to an unusual timing sequence for vitellogenin production. In most insects, vitellogenin first appears in the blood of the adult at about the time that yolk deposition begins. However, most saturniids store a substantial quantity of this protein in the blood of the pupae well before the ovaries are able to use it (Telfer, 1954). Although the experiments of Williams (1952) with Cecropia clearly indicated that the ovarian components of yolk production are emancipated from juvenile hormone control, the possibility remained that the synthesis of vitellogenin still requires this hormone.

In this report, the effects of allatectomy of the early fourth and fifth larval instar of Hyalophora cecropia silkworm moths on the initial appearance of vitellogenin during larval-pupal molt and on the incorporation of amino acids into this protein during the pupal-adult molt, as well as the possible stimulation of vitellogenin synthesis in isolated pupal abdomen by a synthetic juvenile hormone, are described.

\section{Materials and Methods}

\section{Experimental animals}

Silkworms, Hyalophora cecropia, were raised on wild black cherry (Prunus sp.) in the field and sexed and staged according to Telfer (1967). Diapausing pupae were maintained at $5^{\circ} \mathrm{C}$, and adult development was initiated by placing the pupae at $25^{\circ}$ C. Pharate adults were also staged according to Telfer (1967).

Corpora allata and corpora cardiaca complexes were excised surgically (referred to as allatectomy hereafter; see Williams, 1961) from early fourth and fifth instar female larvae within three days after molting as described by Williams (1961). Following surgery, a small piece of Gelfoam (Upjohn) was put over the wound,

I Supported by Biomedical Science Support Grant \#RR-07088 and University of Tennessee faculty research award. 
and the caterpillars were placed at $6^{\circ} \mathrm{C}$ for about six hours and then returned to a netted cherry tree in the field. They were collected after cocoon construction and were examined and killed at the sign of tanning of the abdomen. Diapausing female pupae were allatectomized according to Williams (1961). The wound was sealed with a plastic cover glass. Control animals were similarly treated surgically, except the endocrine glands were not excised. Isolated abdomens were prepared from diapausing pupae by the method of Williams (1947), except that the midgut which is not involved in vitellogenin synthesis was excised. A tiny hole, for injection purposes, sealed with wax was made on the plastic cover glass used to cover the wound.

\section{Immunochemical methods}

The preparation of antibodies against vitellogenin, and their use in precipitating labeled vitellogenin from blood were described previously (Pan, 1971).

Oudin's single immunodiffusion test was used primarily for the detection of vitellogenin and was done according to Pan (1971). Ouchterlony double immunodiffusion was performed on microscope slides employing $0.8 \%$ agarose (Bio-Rad) dissolved in $0.15 \mathrm{M} \mathrm{NaCl}$ buffered with phosphates $(\mathrm{pH} 7.2)$. The wells were cut with a \#13 gauge hollow needle. The distance between center and peripheral wells was $5 \mathrm{~mm}$. Staining and recording of the precipitin bands are reported elsewhere (Pan and Wyatt, 1971).

\section{Acrylamide gel electrophoresis}

Disc acrylamide gel electrophoresis was done according to Davis (1964), with Bio-Rad model 150A electrophoresis cells, except $4 \%$ gel was employed and spacer gel was omitted. Sample was suspended in $40 \%$ sucrose made in running buffer. One per cent fast green FCF in $7 \%$ acetic acid was used to stain the protein bands. The vitellogenin band was determined by placing unfixed gels on specific antibodies mixed in $0.8 \%$ agarose and the position of the precipitin band was compared with bands in stained gels.

\section{Labelling of vitellogenin in vivo}

Except as noted, experimental animals were injected with $0.1 \mathrm{mCi}{ }^{3} \mathrm{H}$-leucine (specific activity $5 \mathrm{Ci} / \mathrm{mm}$, New England Nuclear Corp.) in $0.1 \mathrm{ml}$ distilled water, with a few crystals of phenylthiourea added to prevent melanin formation in the animal. Following treatment, animals were held at $25^{\circ} \mathrm{C}$ and bled 12 hours after the injection. The preparation of blood for the determination of vitellogenin label and total blood protein label is reported in Pan (1971).

\section{Results}

Synthesis of vitellogenin in allatectomized pharate adults

It has been reported that, during late pharate adult development of $H$. cecropia, more than half of the total blood protein radioactivity, following a single injection of tritiated leucine, was found to be in vitellogenin (Pan, 1971). Thus, this stage 
should be ideal for studies on the effect of the corpora allata on the synthesis of vitellogenin. The corpora allata-corpora cardiaca complexes were therefore removed from several pre-chilled diapausing female pupae. Operated pupae were allowed to initiate pharate adult development at $25^{\circ} \mathrm{C}$. On day 18 of pharate adult development, when vitellogenin synthesis is at its peak (Pan, 1971), experimental and control animals were each injected with ${ }^{3} \mathrm{H}$-leucine. Blood was collected 12 hours later and processed to determine the vitellogenin label and total blood protein label (see Materials and Methods). The results, shown in Table I, indicate that removal of the corpora allata in the pupal stage did not affect the incorporation of leucine into vitellogenin $(P>0.5)$ or total blood protein $(P>0.2)$ in late pharate adult development. When the vitellogenin label is expressed as a percentage of the total protein label $(\mathrm{V} / \mathrm{T} \%$ in Table $\mathrm{I})$, no difference was observed between the experimental and control $(P>0.2)$. The expression of proportional incorporation as a percentage of total incorporation is a more meaningful method of relating specific blood protein synthesis, as has been discussed elsewhere (Pan and Wyatt, 1976).

\section{Appearance of vitellogenin in pupae allatectomized as larvae}

Although the results shown in the previous section clearly demonstrate that corpora allata are not required for the synthesis of vitellogenin in pharate adult Cecropia, the apparent normal synthesis of vitellogenin in these animals could be explained as the result of persistence of long-lived vitellogenin messengers before and after the surgery, in that surgical manipulation was performed months after synthesis of vitellogenin had been initiated (see Pan, 1971). Therefore, the possibility exists that the corpora allata are still necessary for the initiation of vitellogenin synthesis in Cecropia, as in many nonsaturniid insects. Corpora allatacorpora cardiaca complexes were then surgically removed from several dozen early fourth and fifth instar female larvae within three days after molting at a time when vitellogenin is not yet present in the blood, nor would it normally appear for at least one to two weeks after the surgery (Telfer, 1954). The presence of vitellogenin in these allatectomized individuals was then determined shortly before pupation, at which time the concentration of vitellogenin in blood is at maximum in normal animals (Telfer, 1954). The success of the surgery was indicated by the fact that those animals allatectomized at early fourth instar skipped the fifth instar stage entirely and molted into either miniature pupae or miniature pupal-adult

TABLE I

${ }^{3} H$-leucine incorporation into vitellogenin of pharate Cecropia adults allatectomized as pupae.

\begin{tabular}{l|c|c|c}
\hline \hline \multirow{2}{*}{ Animal } & \multicolumn{2}{|c|}{$\mathrm{dpm} \times 10^{3} / 5 \mu \mathrm{l}$ blood* } & V $/ \mathrm{T} \%$ \\
\cline { 2 - 3 } & Vitellogenin & Total blood protein & \\
\hline Allatectomized & $32 \pm 4$ & $53 \pm 5$ & $60 \pm 2$ \\
Control & $29 \pm 2$ & $46 \pm 3$ & $63 \pm 1$ \\
\hline
\end{tabular}

* Mean \pm s.e. $(\mathrm{N}=4)$. 


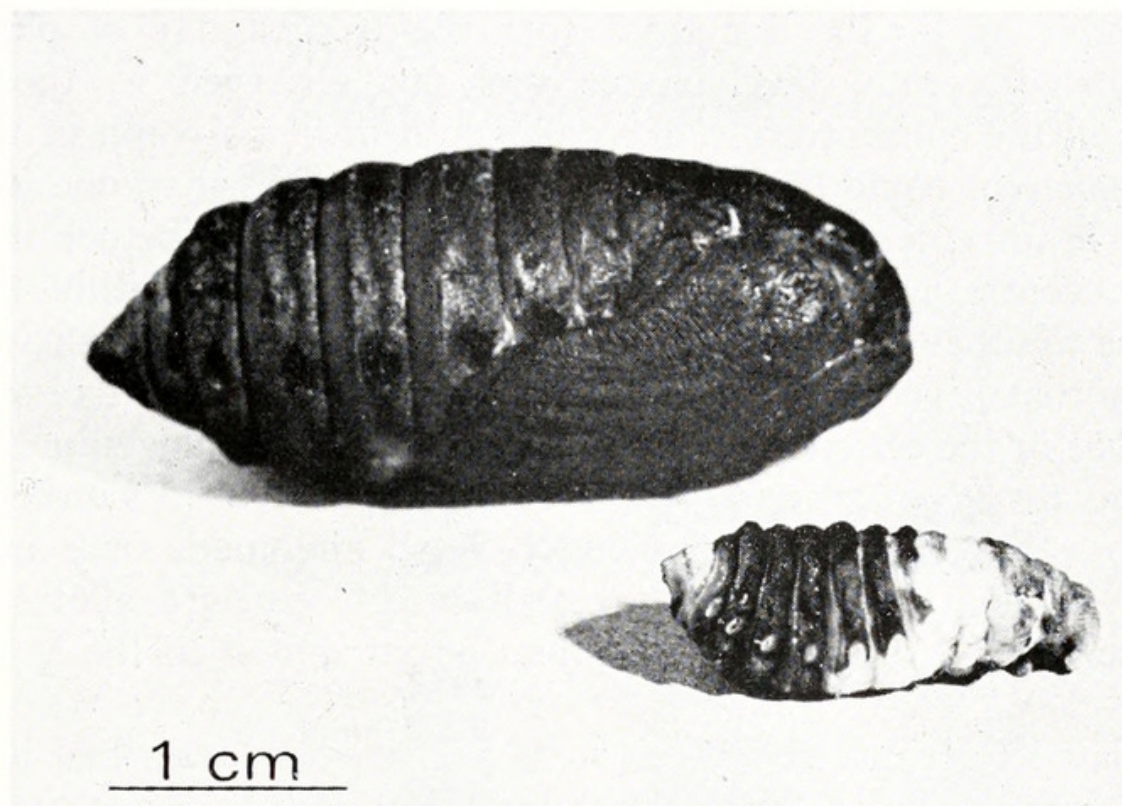

Figure 1. A miniature Cecropia female pupal-adult intermediate transformed from an allatectomized early fourth instar caterpillar. A normal pupa is in the background.

intermediates (Fig. 1); and those allatectomized at early fifth instar molted into pupal-adult intermediates (Fig. 2) essentially as described by Williams (1961). Morphological descriptions and cuticular protein analyses of these intermediates will be reported elsewhere (Willis and Pan, in preparation). Vitellogenin was detectable in all of the miniature pupae as well as the intermediates, indicating that allatectomy at an earlier stage did not prevent the future appearance of vitellogenin. It should be noted that the metamorphosis of these intermediates was so severely disturbed that they could not resorb their molting fluid and consequently could not molt; their old cuticle had to be removed manually. They also contained abnormally low volumes of blood and in several instances blood samples could not be obtained at all. In the later cases, several drops of saline solution were then added to the hemocoel, the washing was collected and the presence of vitellogenin was determined. For this reason, no quantitative analysis was performed on vitellogenin, only its presence was noted by immunodiffusion and several samples were analyzed also by acrylamide gel electrophoresis. Representative samples are shown in Figures 3 and 4.

\section{Juvenile hormone and vitellogenin synthesis in isolated pupal abdomen}

Blumenfeld and Schneiderman (1968) observed that, when diapausing pupae of Antheraea polyphemus (a saturniid) received a dose of the juvenile hormone extract (from male Cecropia adults) and transformed into "second pupae", the concentration of vitellogenin in the blood increased. The effect could be observed as early as 24 hours after hormone treatment. These authors concluded that juvenile hormone affected neither synthesis nor release of vitellogenin, but rather blocked its accumulation by the oocytes. It should be noted that it took 8-10 days for the diapausing animal to become a "second" pupa, whereas normal pupal-adult development requires 23 days. According to Telfer and Rutberg (1960), vitel- 
logenin is not taken up by the oocytes before the twelfth day of pharate adult development. Since ovarian development was not observed in those "second pupae", increases in the concentration of vitellogenin in hemolymph of the "second pupae" of $A$. polyphemus could be related to a situation other than one in which the ovaries were unable to remove vitellogenin from the blood. Whether this increase in vitellogenin concentration resulted from juvenile hormone within the extract, or was in response to other factors present in the extract, remained unclear.

The possibility that juvenile hormone can promote the synthesis of vitellogenin, despite the fact that in the absence of the same hormones, vitellogenin continues to be synthesized, was tested on groups of isolated abdomens with a synthetic juvenile hormone $(d l-\mathrm{JH})$. The advantage of using isolated abdomens over intact pupae is that the brain, ecdysial glands, corpora cardiaca and corpora allata are all excluded and any observed stimulation could then be attributed to the injected compound alone.

Groups of isolated Cecropia abdomens were prepared as described in Materials and Methods and kept at $25^{\circ} \mathrm{C}$ for at least two months before use, when the enhanced blood protein synthesis due to injury finally returned to the normal diapausing level (Telfer and Williams, 1960). Ten $\mu \mathrm{g}$ of Röller's JH-I in olive oil

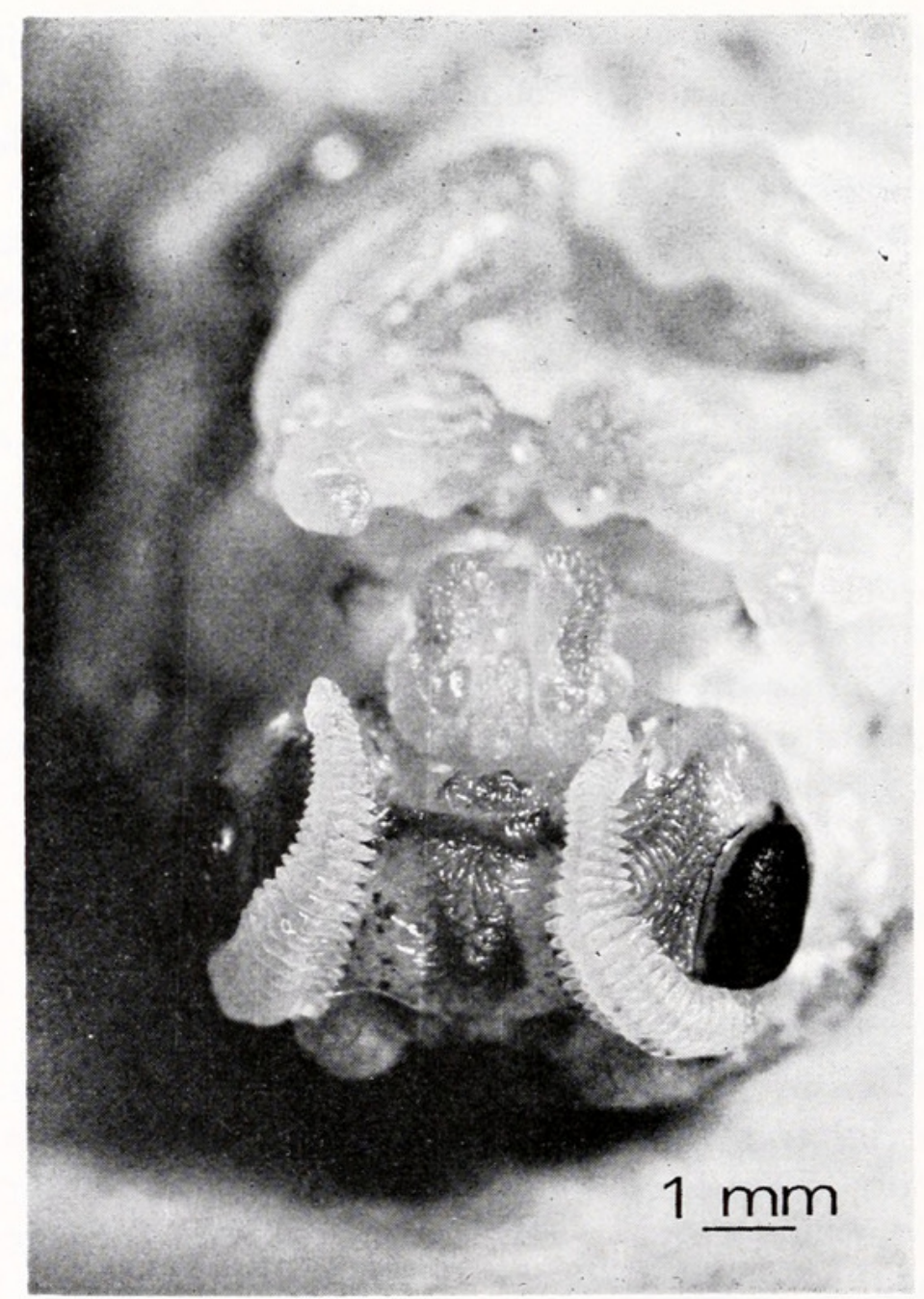

Figure 2. Close-up of a Cecropia female pupal-adult intermediate obtained by allatectomizing an early fifth instar caterpillar. Notice the pigmented compound eyes and barbed antennae. 


\section{ca- ca- $\quad$ bth female male instar}
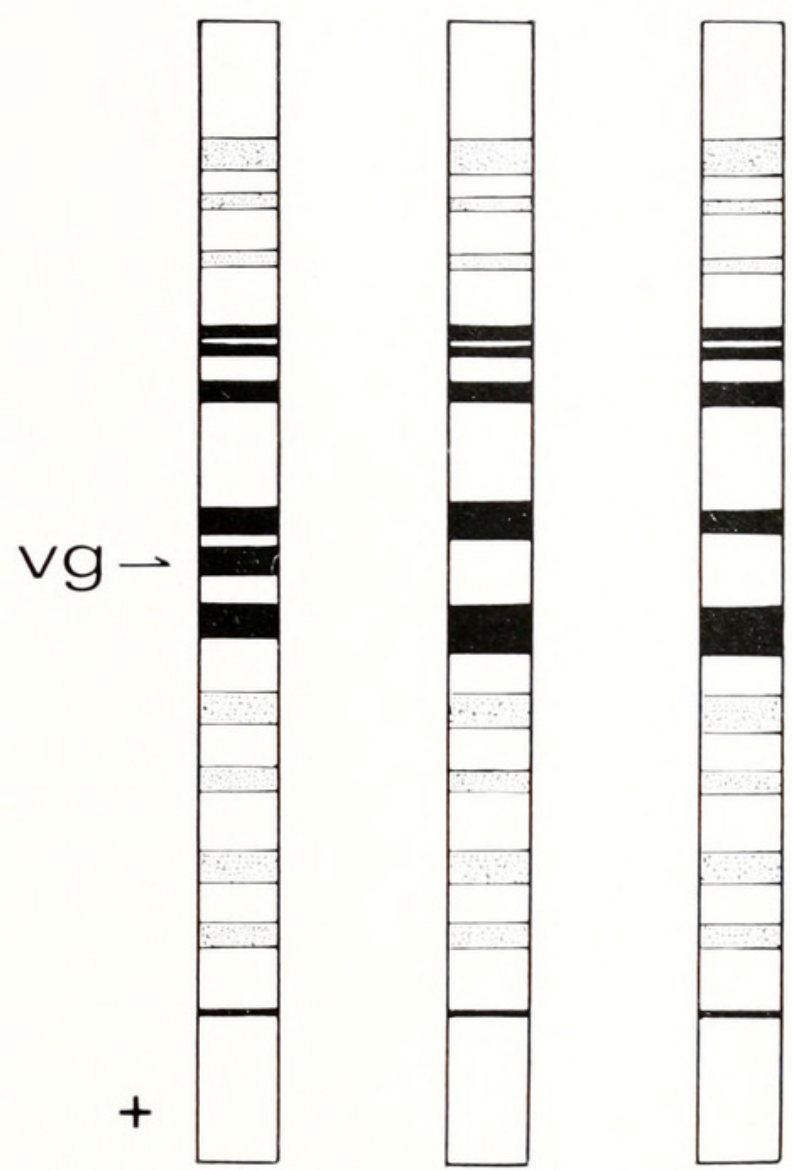

Figure 3. Acrylamide disc gel electrophoresis (4\% gel) of the blood from a miniature Cecropia female pupa (left), a miniature male pupal-adult intermediate (middle) (both from allatectomized early fourth instar larvae) and a normal female fifth instar caterpillar (right). Vitellogenin (vg, arrow) is present only in the blood of the female miniature pupa; ca- indicates allatectomy. Cathode is at top of the gels. Stippled bands represent faintly stained protein bands. Leading band is the tracking dye whose position was also marked with injected India ink before staining.

$(1 \mu \mathrm{g} / \mu \mathrm{l}$ ) (a gift of Dr. G. R. Wyatt, Queen's University, Kingston, Ontario), a dosage sufficient to promote "second pupa" formation with Cecropia pupae (Judith Willis, University of Illinois, personal communication) were injected into each abdomen. Control abdomens received $10 \mu \mathrm{l}$ of olive oil. Hormone and olive oil treatment lasted for $12,24,36$ and 72 hours in respective groups. Six hours before each abdomen was opened for blood sample collection, $20 \mu \mathrm{Ci}$ of ${ }^{3} \mathrm{H}$-leucine was administered to label the vitellogenin and other proteins. The results are given in Table II.

Based on incorporation into vitellogenin, measured as counts-per-minute (cpm), differences between $\mathrm{JH}$-treated and control groups are not significant $(P>0.3)$, except 72 hours, where the cpm into vitellogenin exceeeded that into the controls $(P>0.05)$. However, the significance of this 72 hour difference is questionable, since differences between 12 and 72 hour JH-treated animals are not significant $(P>0.1)$. Differences are also not observed $(P>0.4)$ at either 24 or 48 hours, 


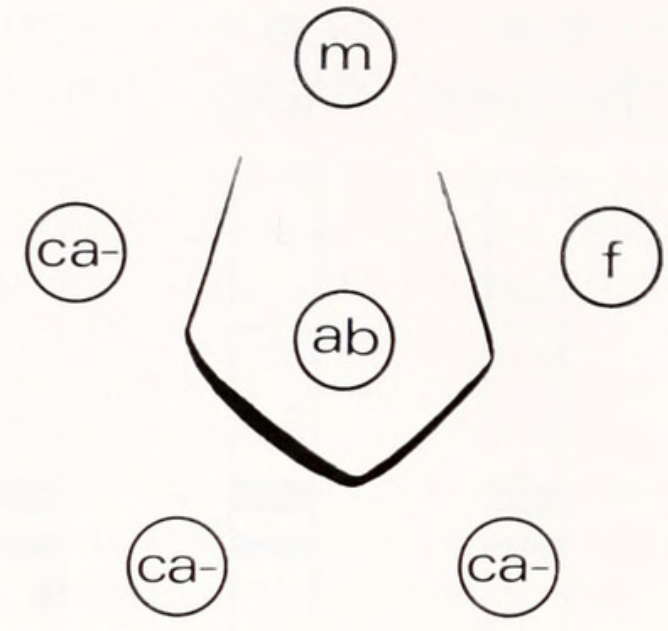

FIGURE 4. Ouchterlony's double immunodiffusion plate showing the presence of vitellogenin in the blood of three Cecropia female pupal-adult intermediates (ca-) transformed from allatectomized early fifth caterpillars, and a normal female diapausing pupa (f). Vitellogenin is absent from the blood of a normal male diapausing pupa $(\mathrm{m})$. The center well (ab) contained antiserum specific for vitellogenin.

as compared to the 12 hour $\mathrm{JH}$-treated group. When comparisons were made between the respective controls, no differences were noted $(P>0.5)$. Thus, incorporation into vitellogenin does not increase over a 72 hours period following $\mathrm{JH}$ administration into isolated abdomens.

A more meaningful method of analyzing vitellogenin incorporation is to normalize any stage-specific differences by expressing vitellogenin incorporation as a percentage of the total label incorporated ( $\mathrm{V} / \mathrm{T} \%$ in Table II). This type of analysis also failed to uncover differences in vitellogenin incorporation following 72 hours of $\mathrm{JH}$ treatment $(P>0.5)$. Therefore, $\mathrm{JH}$ does not appear to stimulate the synthesis of vitellogenin in isolated Cecropia abdomens.

The general trend in increase in total blood protein incorporation in both $\mathrm{JH}$ treated and control groups over a period of 72 hours can be attributed to the injury response (see Pan, 1971). Since cpm differences between JH-treated animals and controls of respective time points are not observed $(P>0.5)$, JH does not seem to

TABLE II

${ }^{3} \mathrm{H}$-leucine incorporation into vitellogenin of isolated Cecropia abdomens treated with juvenile hormone.

\begin{tabular}{|c|c|c|c|c|}
\hline \multirow{2}{*}{$\begin{array}{c}\text { Hours after JH } \\
\text { treatment }\end{array}$} & & \multicolumn{2}{|c|}{$\mathrm{cpm} / 5 \mu \mathrm{l}$ blood* } & \multirow{2}{*}{$\mathrm{V} / \mathrm{T} \%$} \\
\hline & & Vitellogenin & Total blood protein & \\
\hline \multirow[t]{2}{*}{12} & $\mathrm{JH}$-treated & $21 \pm 13$ & $225 \pm 93$ & $7.5 \pm 2.6$ \\
\hline & Control & $28 \pm 23$ & $232 \pm 158$ & $8.9 \pm 2.4$ \\
\hline \multirow[t]{2}{*}{24} & JH-treated & $33 \pm 9$ & $512 \pm 327$ & $8.9 \pm 2.5$ \\
\hline & Control & $24 \pm 5$ & $296 \pm 144$ & $10.8 \pm 2.8$ \\
\hline \multirow[t]{2}{*}{48} & $\mathrm{JH}$-treated & $32 \pm 3$ & $421 \pm 132$ & $9.5 \pm 3.0$ \\
\hline & Control & $31 \pm 15$ & $493 \pm 104$ & $5.7 \pm 1.8$ \\
\hline \multirow[t]{2}{*}{72} & JH-treated & $48 \pm 5$ & $672 \pm 32$ & $7.1 \pm 0.6$ \\
\hline & Control & $27 \pm 3$ & $539 \pm 193$ & $6.2 \pm 2.2$ \\
\hline
\end{tabular}

${ }^{*}$ Mean \pm s.e. $(\mathrm{N}=3)$. 
stimulate the synthesis of other blood proteins as a whole as well, although analysis of the individual protein component is necessary to clear up this point.

Experiments were terminated following 72 hours of treatment because preTiminary experiments employing JH extract from adult male Cecropia silkmoths (see Williams, 1956; Gilbert and Schneiderman, 1960) failed to cause stimulation of vitellogenin synthesis over a two to fourteen day period (Pan, unpublished).

\section{Discussion}

Three lines of complementary evidence are presented in this report, indicating that the corpora allata and juvenile hormone are not required for the initial appearance and synthesis of vitellogenin in the Cecropia silkworm.

Wigglesworth (1964), in discussing why a hormonal stimulus should be needed by most insects for the full activity of the reproductive cycle, suggests that because egg production in most insects, like molting, is a cyclical process; it is desirable for the insects to have some mechanism for restraining the initiation of egg formation until food and other aspects of the environment are all appropriate. Thus, in Rhodnius, where eggs are produced after each blood meal, hormonal regulation is necessary (Wigglesworth, 1936); whereas in the parthogenetic stick insect, Dixippus, in which feeding and egg production are continuous processes in the adult female, a hormonal control is not needed. Removal of the corpora allata does not influence yolk formation (Pflugfelder, 1937; other examples, see Engelmann, 1970). Since the synthesis of vitellogenin is an integral part of egg formation, there is no reason to doubt that its control too has not been under the same selection pressures.

The adult Cecropia silkmoth has all its nutrients provided by the feeding caterpillar and completes egg formation prior to adult emergence. The moth, in its short adult life, does little other than mate and lay its preformed eggs. A hormonal control mechanism for egg formation is therefore not necessary. Thus, the synthesis of vitellogenin is programmed as a component of metamorphosis rather than as, in most insects, an independent event. It should be pointed out that in several nonsaturniid species of Lepidoptera, in which egg formation depends upon feeding or drinking by the adults, the corpora allata are definitely required for vitellogenesis (see review by Wyatt, 1972; Doane, 1973), and the dependence of juvenile hormone for the induction of vitellogenin synthesis has been demonstrated in the Monarch butterfly (Pan and Wyatt, 1976).

The increase of vitellogenin observed by Blumenfeld and Schneiderman (1968) in intact pupae which received juvenile hormone extract requires some conjecture. Recall that the juvenile hormone extract is capable of stimulating the ecdysial glands to secrete ecdysone (Gilbert and Schneiderman, 1959; Williams, 1959). Ecdysone release can in turn cause the initiation of adult development (to become second pupae). Consequently, the synthesis of vitellogenin increases as it does during normal pharate adult development (Pan, 1971), and its concentration in blood rises.

I thank Dr. William H. Telfer for his advice and help; Dr. Robin A. Wallace for his generosity in letting me use his laboratory facilities and his farm to raise 
Cecropia caterpillars; Dr. G. R. Wyatt for a gift of JH ; and Dr. Arthur M. Jungreis for his help in rearing Cecropia and critical reading of the manuscript.

\section{SUMMARY}

1. The involvement of corpora allata and juvenile hormone in vitellogenin synthesis in the Cecropia silkworm was examined.

2. Allatectomy of diapausing pupae did not alter the pattern of ${ }^{3} \mathrm{H}$-leucine incorporation into vitellogenin during their late pharate adult development.

3. Allatectomy of early fourth and fifth instar caterpillars did not prevent the appearance of vitellogenin in these operated animals when they had transformed into miniature pupae or pupal-adult intermediates.

4. Injection of a synthetic $d l-J H$ into isolated diapausing abdomens did not stimulate the incorporation of ${ }^{3} \mathrm{H}$-leucine into vitellogenin.

5. It is concluded that corpora allata and juvenile hormone are not required for the initial appearance and synthesis of vitellogenin in the Cecropia silkworm.

\section{Note AdDEd IN PRESS}

Evidence that miniature pupae are indeed morphologically complete has now been obtained. Following one year storage at room temperature, one male miniature pupa that had been allatectomized in the early fourth larval instar developed and eclosed into a perfect miniature adult moth.

\section{LITERATURE CITED}

Blumenfeld, M., And H. A. Schneiderman, 1968. Effect of juvenile hormone on the synthesis and accumulation of a sex-limited blood protein in the polyphemus silkmoth. Biol. Bull., 135 : 466-475.

Davis, B. J., 1964. Disc electrophoresis-II. Method and application to human serum proteins. Ann. N.Y. Acad. Sci., 121: 404-427.

Donne, W. W., 1973. Role of hormones in insect development. Pages 291-497 in S. J. Counce and C. H. Waddington, Eds., Insects: developmental systems. Academic Press, London.

Engelmann, F., 1970. The physiology of insect reproduction. Pergamon Press, Oxford, 307 pp.

Gilbert, L. I., And H. A. Schneiderman, 1959. Prothoracic gland stimulation by juvenile hormone extracts of insects. Nature, 184: 171-173.

Gilbert, L. I., and H. A. Schneiderman, 1960. The development of a bioassay for the juvenile hormone of insects. Trans. Am. Microsc. Soc., 70: 38-67.

PAn, M. L., 1971. The synthesis of vitellogenin in the cecropia silkworm. J. Insect Physiol., $17: 677-689$.

Pan, M. L., and G. R. Wyatt, 1971. Juvenile hormone induces vitellogenin synthesis in the Monarch butterfly. Science, 174: 503-505.

Pan, M. L., And G. R. Wyatt, 1976. Control of vitellogenin synthesis in the Monarch butterfly by juvenile hormone. Dev. Biol., $54: 127-134$.

Pan, M. L., W. J. Bell, And W. H. Telfer, 1969. Vitellogenic blood protein synthesis by insect fat body. Science, $165:$ 393-394.

Pflugfelder, O., 1937. Bau, Entwicklung und Funktion der Corpora allata und cardiaca von Dixippus morosus Br. Z. Wiss. Zool., 149: 477-512.

Telfer, W. H., 1954. Immunological studies of insect metamorphosis. II. The role of a sexlimited blood protein in egg formation by the cecropia silkworm. J. Gen. Physiol., 37 : 539-558. 
Telfer, W. H., 1965. The mechanism and control of yolk formation. Annu. Rev. Entomol., $10: 161-184$.

Telfer, W. H., 1967. Cecropia. Pages 173-182 in F. H. Wilt and N. K. Wessells, Eds., Methods in developmental biology. T. Y. Crowell Co., New York.

Telfer, W. H., and L. D. Rutberg, 1960. The effects of blood protein depletion on the growth of oocytes in the cecropia moth. Biol. Bull., 118: 352-366.

Telfer, W. H., and C. M. Williams, 1960. The effects of diapause, development, and injury on the incorporation of radioactive glycine into the blood proteins of the cecropia silkworm. J. Insect Physiol., 5: 61-72.

Wigglesworth, V. B., 1936. The function of the corpus allatum in the growth and reproduction of Rhodnius prolixus. Q. J. Microsc. Soc., 79: 91-121.

Wigglesworth, V. B., 1964. The hormonal regulation of growth and reproduction in insects. Adv. Insect Physiol., $2: 247-336$.

Williams, C. M., 1947. Physiology of insect diapause. II. Interaction between the pupal brain and prothoracic glands in the metamorphosis of the giant silkworm, Platysamia cecropia. Biol. Bull., 93: 89-98.

Williams, C. M., 1952. Physiology of insect diapause. IV. The brain and prothoracic glands as an endocrine system in the Cecropia silkworm. Biol. Bull., 103: 120-138.

Williams, C. M., 1956. The juvenile hormone of insects. Nature, 178: 212-213.

Williams, C. M., 1959. The juvenile hormone. I. Endocrine activity of the corpora allata of the adult Cecropia silkworm. Biol. Bull., 116: 323-338.

Williams, C. M., 1961. The juvenile hormone. II. Its role in the endocrine control of moulting, pupation, and adult development in the Cecropia silkworm. Biol. Bull., 121: $572-585$.

Wyatt, G. R., 1972. Insect hormones. Pages 385-490 in G. Litwak, Ed., Biochemical actions of hormones, Vol. 2. Academic Press, New York. 


\section{$2 \mathrm{BHL}$ Biodiversity Heritage Library}

Pan, M. L. 1977. "JUVENILE HORMONE AND VITELLOGENIN SYNTHESIS IN THE CECROPIA SILKWORM." The Biological bulletin 153, 336-345.

https://doi.org/10.2307/1540439.

View This Item Online: https://www.biodiversitylibrary.org/item/17444

DOI: https://doi.org/10.2307/1540439

Permalink: https://www.biodiversitylibrary.org/partpdf/32257

\section{Holding Institution}

MBLWHOI Library

\section{Sponsored by}

MBLWHOI Library

\section{Copyright \& Reuse}

Copyright Status: In copyright. Digitized with the permission of the rights holder.

License: http://creativecommons.org/licenses/by-nc-sa/3.0/

Rights: https://biodiversitylibrary.org/permissions

This document was created from content at the Biodiversity Heritage Library, the world's largest open access digital library for biodiversity literature and archives. Visit BHL at https://www.biodiversitylibrary.org. 